\title{
On Fluctuations in the Cross-Sectional Distribution of Unemployment Rates
}

\author{
Fariba Hashemi ${ }^{1}$ \\ ${ }^{1}$ Swiss Federal Institute of Technology, Lausanne, Switzerland \\ Correspondence: Fariba Hashemi, Swiss Federal Institute of Technology, College of Management of \\ Technology, CH 1015 Lausanne, Switzerland. Tel: 41-21-693-6367. E-mail: Fariba.Hashemi@epfl.ch
}

Received: October 17, 2011

Accepted: June 14, $2012 \quad$ Published: July 10, 2012

doi:10.5539/ijef.v4n8p29

URL: http://dx.doi.org/10.5539/ijef.v4n8p29

\begin{abstract}
The cross-sectional distribution of unemployment rates has been relatively neglected compared to the study of unemployment rate differences across countries over time. This paper helps fill the gap. A drift-diffusion model is proposed to describe the dynamics of the cross-sectional distribution of unemployment rates. The model is fitted to the evolution of unemployment rate distribution across five regions, to estimate the natural rates and speeds of convergence to natural rates once an economy is hit by an exogenous shock. Given the importance of the natural rate for gauging the state of the business cycle, the outlook for future inflation, and the appropriate stance of monetary policy, techniques for its estimation would not be without merit.
\end{abstract}

Keywords: labor market dynamics, natural rate of unemployment, diffusion processes

\section{Introduction}

The study is motivated by the observation that the rate of unemployment across different states within a country, and countries within a region varies as a function of time. It would not be unreasonable to assume that a long-run distribution of the equilibrium or natural rate of unemployment exists with a certain mean and variance. It is hypothesized that over time a set of similar countries share the same natural rate of unemployment. Given an exogenous shock, the ensemble of states considered tends to converge to this long-run equilibrium. We build a theory of the distribution of the rate of unemployment as a drift-diffusion process, and propose a dynamic stochastic model to address the evolution of the cross-sectional distribution of unemployment rates. An empirical application fits the proposed model to the evolution of unemployment rate distribution across five different sets of countries: a) 52 states of the U.S. b) OECD member countries c) OECD Europe d) a handful of the major economies in South East Asia and e) a handful of major economies in South America. The results are novel. Given that estimates of the natural rate of unemployment and its time variation are typically imprecise and far from robust, the present paper suggests that diffusion may be a preferable technique for the estimation of the natural rate of unemployment and for monitoring labor market dynamics.

\section{Literature Review}

"Dynamic and stochastic elements have played an important role in shaping real-world outcomes. In The Wealth of Nations, Adam Smith described what he called the natural price of a commodity. The Wealth of Nations was a portrait of a dynamic stochastic model of a perfectly competitive industry, in which Smith's natural price was simply the deterministic steady state equilibrium price." (Rogerson 1997, p. 90). Likewise, Friedman's natural rate concept can be viewed as the deterministic steady state equilibrium rate of unemployment. Friedman argued that unemployment has an equilibrium or natural rate, determined not by the amount of demand in the economy but by the structure of the labor market. In his (1968) Presidential Address to the American Economic Association, Friedman echoed Adam Smith and described an economy in which at any moment in time, "actual unemployment may be either above or below its natural rate, but is continually gravitating toward it". In other words, as an economy adjusts to any average rate of inflation, unemployment returns to its natural rate (Rogerson 1997, p. 90). In support of Friedman's thesis, one may note that the rate of unemployment across different states within a country, and countries within a region, varies as a function of time. It would therefore not be unreasonable to assume the existence of an equilibrium or natural distribution of unemployment rates, towards which an out-of-equilibrium labor market tends to gravitate. 
Standard economics literature on the determinants of unemployment is built on two main ideas: i) actual unemployment deviates from equilibrium unemployment as shocks hit the economy, and ii) equilibrium unemployment is determined by structural and institutional factors that differ across countries and even regions within the same country. The natural rate of unemployment is a concept frequently employed in fiscal and monetary policy deliberations. National governments use estimates of the natural rate to compute potential GDP, which in turn is used to make budget projections that affect decisions about federal spending and taxation. Central banks consider estimates of the natural rate to determine the likely course of inflation and what actions they should take to preserve price stability (Dickens 2009). It is therefore not surprising that the economics literature is rich with theories which can be employed to draw inferences about the equilibrium distribution of unemployment rates (Forder 2010, Gali 2010, Karanassou, Sala and Snower 2010, Buianovsky and Presley 2009, Petrongolo and Pissarides 2009, King and Morley 2007, Shimer 2005, Ball and Mankiw 2002, Yashiv 2000).

As it turns out however, estimates of the natural rate and its time variation tend to be rather imprecise and far from robust. The reason is that these estimates are typically obtained from estimates of the Phillips curve which in itself is problematic given the complicated relationship between the inflation rate, the lags in the inflation rate, the unemployment rate, its own lags, inflationary expectations, and supply shocks. In this paper, the characterization of the equilibrium unemployment in the standard literature is re-visited. It is considered that over time a set of countries share the same natural rate of unemployment. This assumption is more realistic across the states of the U.S., but also increasingly realistic across other regions which are going through integration and harmonization efforts. Our aim is to model the evolution of density of cross-sectional distribution of unemployment rates, and to build up a tractable structure for the analysis of the diffusion of shocks across its space.

\section{The Model}

Consider a region consisting of $N$ states or countries, with differing rates of unemployment. Assume the existence of a long-run equilibrium or natural distribution of unemployment with a certain unknown mean and variance, towards which the distribution evolves over time. In general, one can study a Markov process generated by a matrix of transitions from one rate of unemployment to another, where the Markov process can be treated as unemployment rate diffusion. Then one can apply the general Fokker-Planck equation to describe evolution in time of unemployment. Hence, assuming that the rate of unemployment behaves like a stochastic process and that it is continuous and Markovian, consider the most natural candidate; a classical linear stochastic differential equation driven by Gaussian white noise:

$$
d S_{t}+\lambda\left(u-S_{t}\right) d t=\sqrt{ }(2 \varepsilon) d B
$$

where $S_{t}$ denotes rate of unemployment. $\lambda$ denotes velocity of adjustment to stationary equilibrium interpreted as unemployment rate adjustment (which for simplicity we assume constant), $u$ denotes the mean of the stationary equilibrium distribution, $\varepsilon>0$ is a constant diffusion parameter, and $B$ is the Brownian motion. Equilibrium in this paper refers to a statistical equilibrium, characterized by a stationary probability distribution of unemployment rates. This equilibrium can be associated with level of unemployment which is in line with the natural rate of unemployment.

More precisely, consider the basic conservation law, with $q$ a flux of probability, interpreted as the spread, or number of states exiting an unemployment rate interval. In this paper it is assumed that the spread is made of two different parts: a drift $q_{c}$ and some diffusion $q_{d}$. Drift describes supply and demand forces at work, and diffusion describes random processes.

Thus,

$$
q=q_{c}+q_{d}
$$

The term $q_{c}$ measures the portion of the function $f$ transported by the drift velocity. For the drift spread, there exists some long-run equilibrium distribution of unemployment rates towards which the distribution drifts, based on a linear distance from equilibrium. I.e., a flux towards the equilibrium distribution. So,

$$
q_{c}(s, t)=\lambda(u-s) f(s, t)
$$

where $s$ measures some relevant aspect of unemployment rate in logarithms. $u$ represents where the mean of the distribution is headed, which we interpret as the natural rate of unemployment, and $\lambda$ denotes the speed of convergence, or the velocity at which unemployment reaches its equilibrium level.

For the diffusion spread, random effects tend to cause a flux from regions of low concentration to regions of high 
concentration. The simplest choice is Fick's law:

$$
q_{d}(s, t)=-\varepsilon \partial f / \partial s(s, t)
$$

where $\varepsilon>0$ is a constant diffusion parameter. Thus we have

$$
q=\lambda(u-s) f-\varepsilon \partial f / \partial s
$$

This is our equation for the density of cross-sectional distribution of unemployment rates. The drift-diffusion mechanism applies to the transition between two long-term equilibriums from $\left(u_{0}, \sigma_{0}\right)$ to $(u, \sigma)$. The process derived from the diffusion model is the size distribution of the population at chosen sequences of times through the observation period. It evolves according to an Ornstein-Uhlenbeck, but with a transition, such that the mean tends to $u$, instead of 0 . From the analytic solution to the model, the dynamics of the distribution can be followed through time, given our initial distribution function $f_{0}$. The dynamics of the proposed model rely on two opposing forces: (i) a mean reversion process, call it drift, meant to describe supply and demand for labor, concentrating the distribution, and (ii) a counteracting diffusion process which flattens the distribution out. Noise is generated by search and learning in the presence of incomplete information and bounded rationality (Levine 2009, Gigerenzer and Selten 2002, Hashemi 2011, Simon 1997, Arrow 1962 and Alchian 1950). Although an equilibrium or natural rate of unemployment exists for each region, this equilibrium is assumed uncertain from the point of view of wage and price setters. Agents take time to coordinate, because they collectively need to learn about price and wage rigidities in the economy. Agents follow no precise law to arrive at this optimum, they search and learn by means of trial and error and imitation. After all, labor markets are in a constant state of flux: some firms are expanding employment, others are reducing employment. In the United States alone, 90,000 jobs are destroyed every working day. However, 90,000 other jobs are also created and this intense turnover is a primary engine of fluctuations (Cahuc and Zylberberg (2006)). This search process generates randomness in the system. The drift-diffusion model proposed in this paper studies the fluctuations around the distribution of unemployment rates and measures the dynamics of convergence towards its long run state, or the natural rate of unemployment.

Remark: Fick's law is well known to govern the transport of mass through diffusive means. There are important analogies between Fick's law of diffusion, Fourier's law of heat conduction, Newton's law of viscosity, Darcy's law of permeability, and Ohm's law of electrical conductance. Fick's original experiments dealt with measuring the concentrations and fluxes of salt, diffusing between two reservoirs through tubes of water. Today, Fick's laws form the core of our understanding of diffusion in solids, liquids, and gases. Hashemi (2000) provides an elaboration of this model, albeit in a different context.

\section{Empirical Application}

\subsection{Data and Descriptive Statistics}

The empirical analysis applies the model to five different data sets of unemployment rates. The first data set pertains to the rate of unemployment for the 52 states of the United States. The data spans from 1976 up to 2010 and consists of a total of 1820 unemployment rates. The second data set pertains to the rate of unemployment for all countries in Europe that are members of OECD (OECD EU). The data spans from 1970 up to 2009, and consists of a total of 662 unemployment rates from 23 countries. The third data set pertains to all members of OECD. A total of 30 countries are reported and 889 unemployment rates are available from year 1970 up to 2009. The fourth data set pertains to the rate unemployment for Asia. The data spans from 1980 up to 2010 for 10 Asian countries, and consists of a total of 230 unemployment rates. The Asian countries included are: China, Hong Kong, Indonesia, Japan, South Korea, Malaysia, Philippines, Singapore, Taiwan and Thailand. The fifth data set pertains to the rate unemployment for South America (SA). The data spans from 1984 up to 2010 for 7 South American countries, and consists of a total of 91 unemployment rates. The South American countries included in the sample are: Argentina, Brazil, Chile, Mexico, Peru, Uruguay and Venezuela. In all cases, observations were available annually, and all data have been collected from the Bureau of Labor Statistics and the World Bank.

Figure 1 illustrates the evolution of unemployment rate from 1984 up to 2009 across the five data sets. It is on these years wherein all five data sets have values. Therefore, the descriptive statistics in Figures 1 and 2 will include the data from 1984 to 2009 only. Moreover, it must be noted that data points graphed are based on the average rate per year for each country (or states in the case of the United States). 


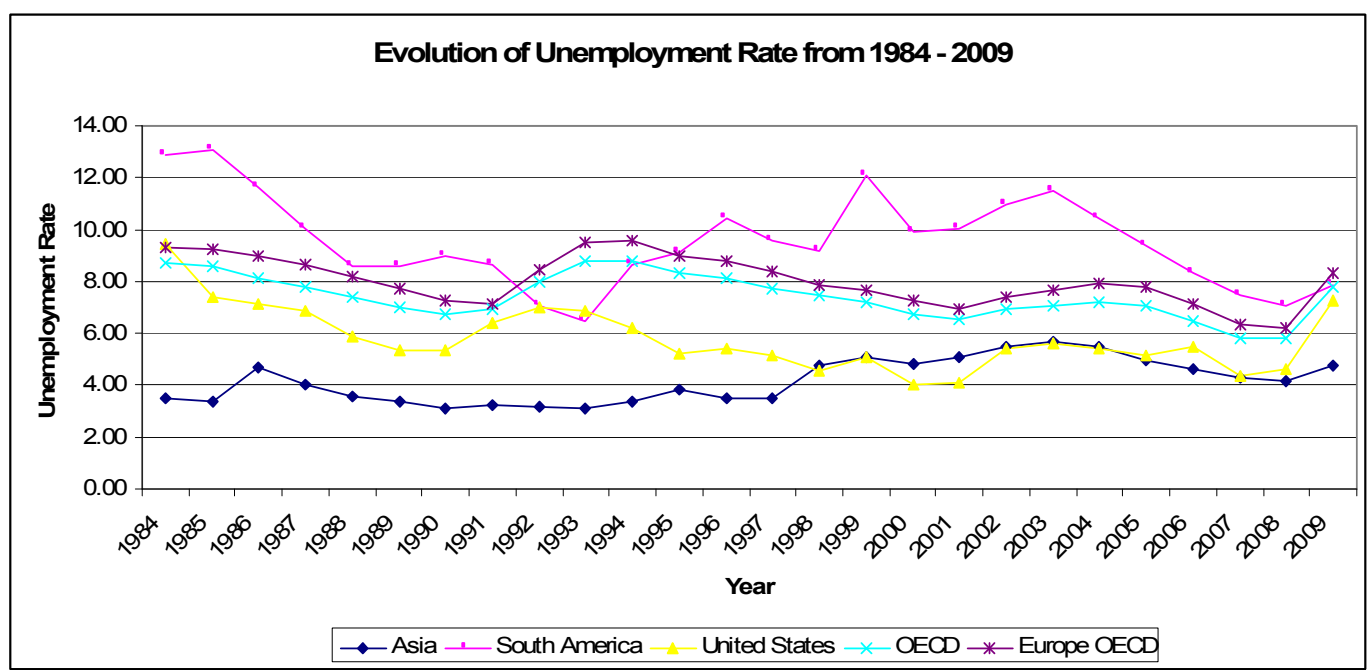

Figure 1. Evolution of Unemployment Rate from 1984 - 2009.

As can be seen, our Asian sample has the lowest but the most stable rate of unemployment and our South American sample on average, has the highest rate with the largest fluctuations. In order to compare countries in terms of the distribution around the mean rate of unemployment, the variance has been investigated. Figure 2 presents the evolution of distribution of unemployment rates for the five regions.
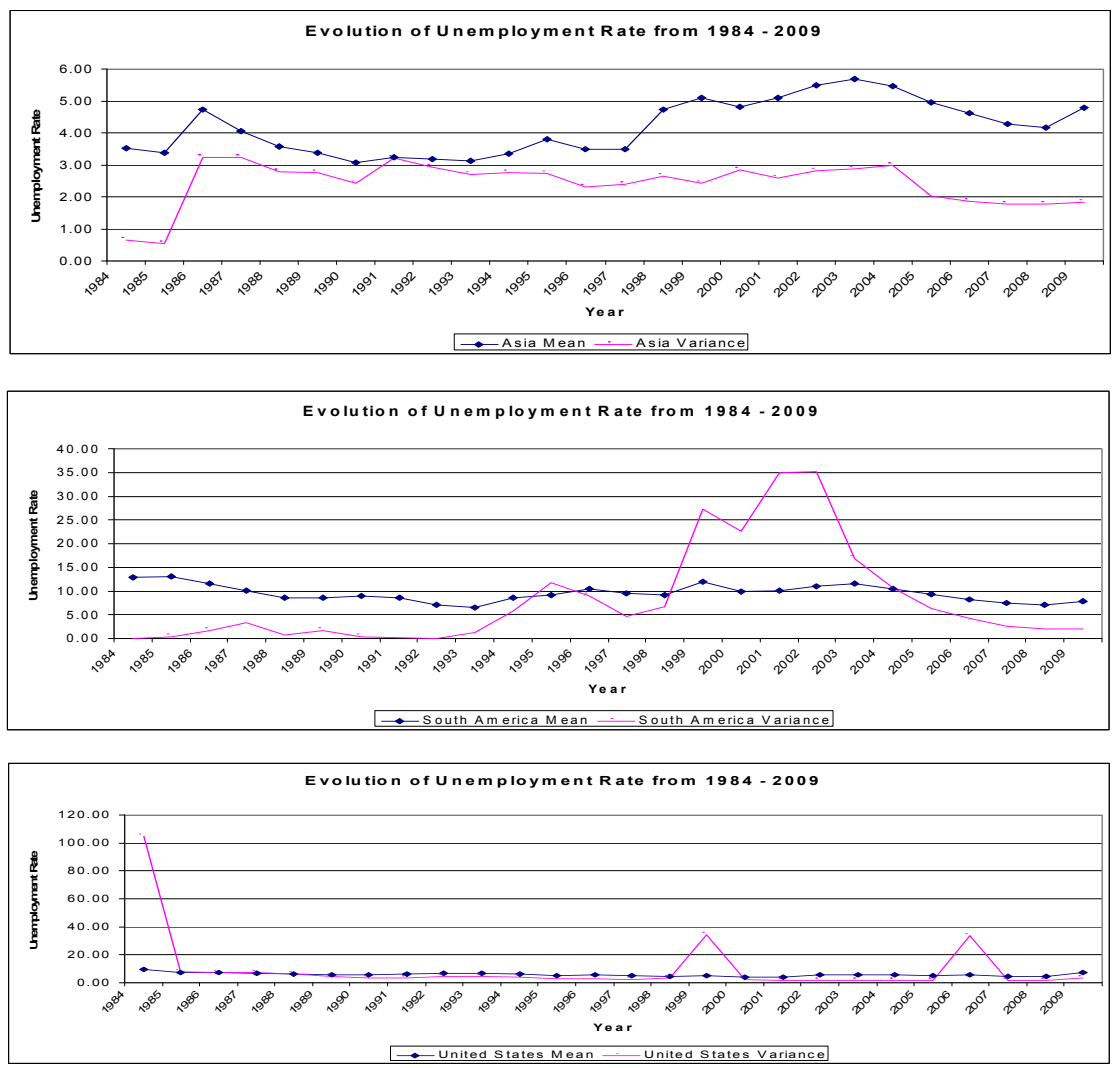

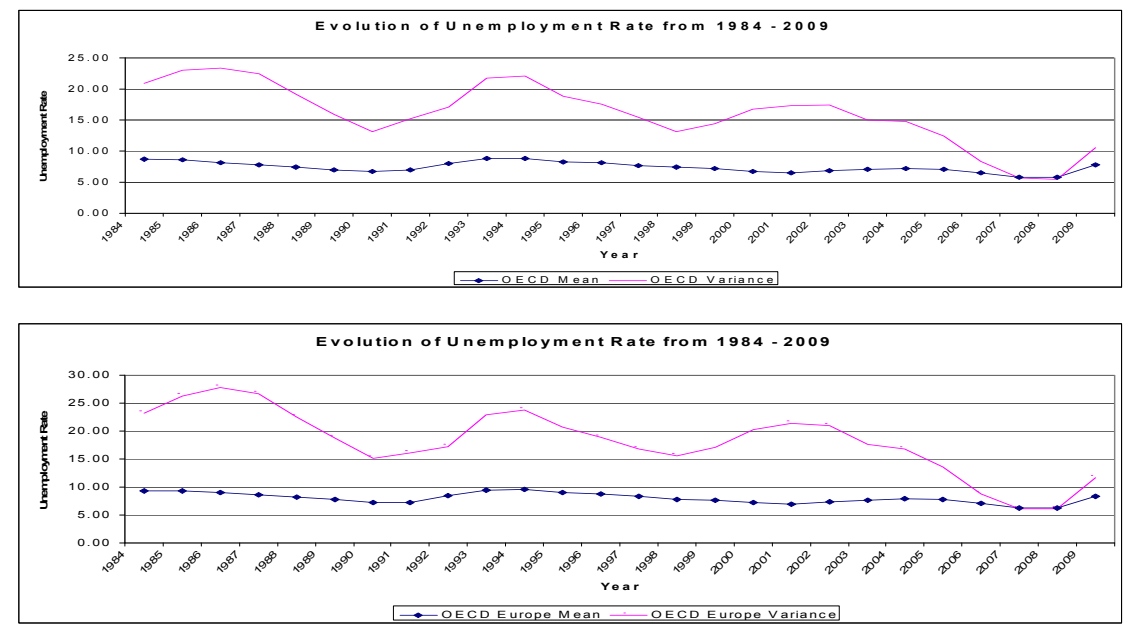

Figure 2. Evolution of Distribution of Unemployment Rates for Asia, South America, the States of the U.S., OECD, and OECD Europe; Mean versus Variance

The first panel in Figure 2 represents Asia. The panel illustrates that fluctuations around the mean unemployment rate significantly decrease from 1986 up to about 1997, however, the variability increases thereafter. This finding may suggest that from 1986 to 1997 the labor markets of our Asian sample were flexible enough to cope with the changing market demands, but may have lost their hold thereafter. This may be partly explained by the Asian financial crisis which began with the devaluation of the Thai Baht in July 1997 and spread like a wave across the region. The second panel illustrates the evolution of distribution of unemployment rates for our South American sample. Like in Asia, there are years where the variability decreases with respect to the mean unemployment rate but only for a while. In fact, during years 1999 to 2002, a sudden upward surge of variability was reported which may suggest that the labor markets of our South American sample may not handle the dynamic nature of their industry as well as those in the United States. One explanation for this variability may be the currency and financial crisis which began in S.E Asia in 1997 and spread like a wave, until it finally arrived in Argentina in 2002. The third panel illustrates the evolution of distribution of unemployment rates for the states of the United States. As can be observed, for most of the years except 1984, 1999, and 2006, the variability of unemployment rate around the mean is relatively small. We observe that only United States has somewhat flattened out the variation of unemployment rates as years pass by. The fourth panel illustrates the evolution of distribution of unemployment rates for OECD member countries. This figure suggests that the labor markets of these countries are having a relatively harder time adjusting, conforming to studies which highlight relatively less flexible labor markets in Europe (Nickell (1997), Nickell, Nunziater and Ochel (2005)). The fifth panel illustrates the evolution of distribution of unemployment rates for OECD Europe, and demonstrates the same trend as compared to our OECD sample.

Table 1 reports some descriptive statistics for the five data sets. It can be observed that Asia has the lowest average unemployment rate among the five data sets and that South America has the highest.

Table 1. Descriptive Statistics for the Five Regions (in logs)

\begin{tabular}{llllll}
\hline & $\mathrm{N}$ & Minimum & Maximum & Mean & Std. Deviation \\
\hline U.S. all data & 1683 & 0.815 & 2.859 & 1.711 & 0.328 \\
Used for fit (variance only) & 1326 & 0.815 & 2.859 & 1.665 & 0.318 \\
OECD all data & 662 & -0.587 & 3.173 & 1.821 & 0.623 \\
Used for fit & 520 & 0.392 & 3.173 & 1.929 & 0.550 \\
Asia all data & 211 & 0.095 & 2.292 & 1.176 & 0.428 \\
S. America all data & 103 & 1.840 & 2.980 & 2.370 & 0.277 \\
OECD Europe all data & 581 & -0.510 & 3.063 & 1.946 & 0.569 \\
\hline
\end{tabular}

Furthermore, it is worth investigating if the means or the averages of the five data sets are different from each other. Table 2 reports the independent samples t-test for all five data sets. The results illustrate that for all 
pair-wise combinations, there is a significant difference between the means of unemployment rates. Here, a significance value of less than $0.05(\mathrm{p}<0.05)$ can be interpreted to mean that the average unemployment rate of the two compared countries are significantly different. Let us take for example the case of Asia and South America, a mean of 4.1746 for Asia and 9.5269 for South America, was deemed not to be significantly different with a significance value $\mathrm{p}<0.001$. This finding is the same throughout the pair wise comparison for all countries (Note: Alpha level is set to 0.05 ).

Table 2. Independent Samples T-test

$95 \%$ Confidence

Interval of the

\begin{tabular}{l|l|l|l|l|l|l}
\hline & $\mathrm{t}$ & $\mathrm{df}$ & Sig.(2-tailed) & Mean Difference & Lower & Upper \\
\hline Asia & 25.403 & 25 & .000 & 4.17462 & 3.8362 & 4.5131 \\
South America & 27.701 & 25 & .000 & 9.52692 & 8.8186 & 10.2352 \\
\hline Asia & 25.403 & 25 & .000 & 4.17462 & 3.8362 & 4.5131 \\
United States & 24.105 & 25 & .000 & 5.79923 & 5.3037 & 6.2947 \\
\hline Asia & 25.403 & 25 & .000 & 4.17462 & 3.8362 & 4.5131 \\
OECD & 44.542 & 25 & .000 & 7.42269 & 7.0795 & 7.7659 \\
\hline Asia & 25.403 & 25 & .000 & 4.17462 & 3.8362 & 4.5131 \\
OECD Europe & 43.811 & 25 & .000 & 8.02308 & 7.6459 & 8.4002 \\
\hline South America & 27.701 & 25 & .000 & 9.52692 & 8.8186 & 10.2352 \\
United States & 24.105 & 25 & .000 & 5.79923 & 5.3037 & 6.2947 \\
\hline South America & 27.701 & 25 & .000 & 9.52692 & 8.8186 & 10.2352 \\
OECD & 44.542 & 25 & .000 & 7.42269 & 7.0795 & 7.7659 \\
\hline South America & 27.701 & 25 & .000 & 9.52692 & 8.8186 & 10.2352 \\
OECD Europe & 43.801 & 25 & .000 & 8.02308 & 7.6459 & 8.4002 \\
\hline United States & 24.105 & 25 & .000 & 5.79923 & 5.3037 & 6.2947 \\
OECD & 44.542 & 25 & .000 & 7.42269 & 7.0795 & 7.7659 \\
\hline United States & 24.105 & 25 & .000 & 5.79923 & 5.3037 & 6.2947 \\
OECD Europe & 43.811 & 25 & .000 & 8.02308 & 7.6459 & 8.4002 \\
\hline OECD & 44.542 & 25 & .000 & 7.42269 & 7.0795 & 7.7659 \\
OECD Europe & 43.811 & 25 & .000 & 8.02308 & 7.6459 & 8.4002 \\
\hline Table 2. Sam & $\mathrm{t}-1 \mathrm{n}$ & & & & \\
\hline
\end{tabular}

Table 2. Sample t-tests for the Five Regions

\subsection{Method of Estimation}

A second order partial differential equation has been proposed to express the dynamics of the distribution of unemployment rates across different regions. The model has five parameters: $u_{0}, u, \varepsilon, \sigma_{0}{ }^{2}$ and $\lambda . u_{0}$ denotes the initial mean of the unemployment distribution (1980), and $u$ denotes where the initial mean is heading, which we associate with the natural rate of unemployment. $\sigma_{0}$ is the standard deviation at time zero (1980), $\varepsilon$ represents the diffusion parameter, and $\lambda$ represents the rate of convergence to the long-run steady state equilibrium.

The model has been fitted to the log unemployment rate as a function of time, using non-linear least squares, and using a two-step procedure. First, the values for $u_{0}, u$ and $\lambda$ were estimated using the expectation of the distribution, expressed by the first moment:

$$
u_{t}=u\left(1-e^{-\lambda t}\right)+u_{0} e^{-\lambda t}
$$

In the second step, the values for $\varepsilon$ and $\sigma_{0}$ were computed using the expression for the second moment of the distribution:

$$
\sigma_{t}^{2}=\sigma_{0}^{2} e^{-2 \lambda t}+\varepsilon / \lambda\left(1-e^{-2 \lambda t}\right)
$$

The diffusive limit, as $t \rightarrow \infty$ of the variance is: $\varepsilon / \lambda$.

Remark: The Ornstein-Uhlenbeck process is the most general normal stationary Markovian process with zero expectations. For $t>T$, the transition density from $(T, s)$ to $(t, y)$ is normal with expectation $e^{-\lambda(r-t)} s$ and variance $\sigma^{2}\left(1-e^{-2 \lambda(r-t)}\right)$. As $t \rightarrow \infty$, the expectation tends to 0 and the variance to $\sigma^{2}$. The analytic solution derived for our diffusion equation is a normal distribution for all $t$. There is the $s e^{\lambda t}$ factor; with a change of variables, it can be 
shown that the solution is normal with a constant multiplied by it.

\subsection{Estimation Results and Model Checks}

Tables 3-4 report estimates for the five model parameters $\lambda, u, u_{0,} \sigma_{0}$ and $\varepsilon$, along with the standard errors and t-values for the two data samples for which a fit was observed, i.e. the United States and OECD.

Table 3. United States Parameter estimates

\begin{tabular}{llll}
\hline Parameter & Value & Std Error. & t-value \\
\hline$\lambda$ & 0.163 & 0.066 & 2.469 \\
$u$ & 1.523 & 0.057 & 26.697 \\
$u 0$ & 3.308 & 0.950 & 3.480 \\
$\sigma_{o}{ }^{2}$ & 0.120 & 0.035 & 3.447 \\
$\varepsilon$ & 0.0003 & 0.002 & 0.181 \\
\hline
\end{tabular}

Table 4. OECD Parameter estimates

\begin{tabular}{llll}
\hline Parameter & Value & Std Error. & t-value \\
\hline$\lambda$ & 0.165 & 0.022 & 7.499 \\
$u$ & 1.972 & 0.039 & 50.331 \\
$u 0$ & 0.317 & 0.113 & 2.809 \\
$\sigma_{o}^{2}$ & 0.675 & 0.228 & 2.955 \\
$\varepsilon$ & -0.003 & 0.007 & -0.523 \\
\hline
\end{tabular}

The following observations can be made concerning the results:

1. The mean and variance of the distributions for the United States and OECD data samples are clearly evolving, suggesting a clear trend for the natural rate of unemployment. This finding corresponds to our theoretical predictions.

2. The speed of convergence to long-run equilibrium or natural rate $\lambda$, varies between the United States and OECD data, and is positive as expected. This velocity is slightly faster for our OECD sample than for our United States sample. This finding is important as it illustrates that the velocity at which unemployment reaches it equilibrium level is not constant, but rather depends on the particular region considered.

Figures $3 \mathrm{a}-\mathrm{e}$ illustrate plots of the mean and variance of the distributions over time, for the five regions. Although a fit was not observed for our Asian, South American, and OECD Europe samples, the plots are reported all the same, which may explain why this might be the case, as they do not seem to converge towards any value.
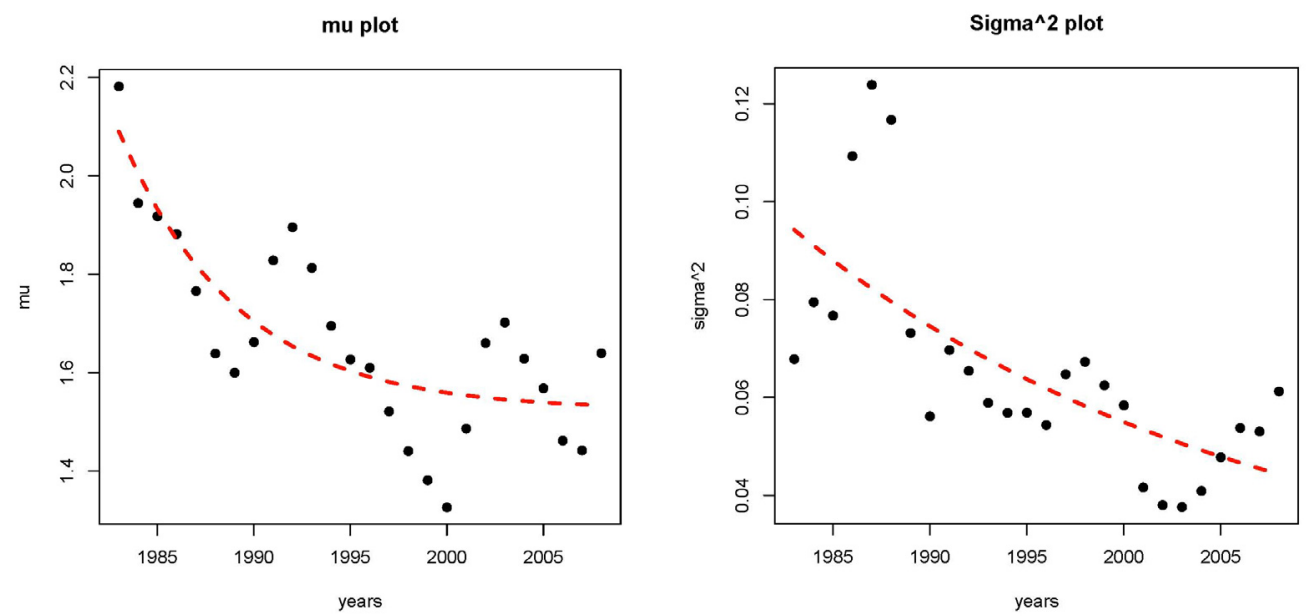

Figure 3a. United States 

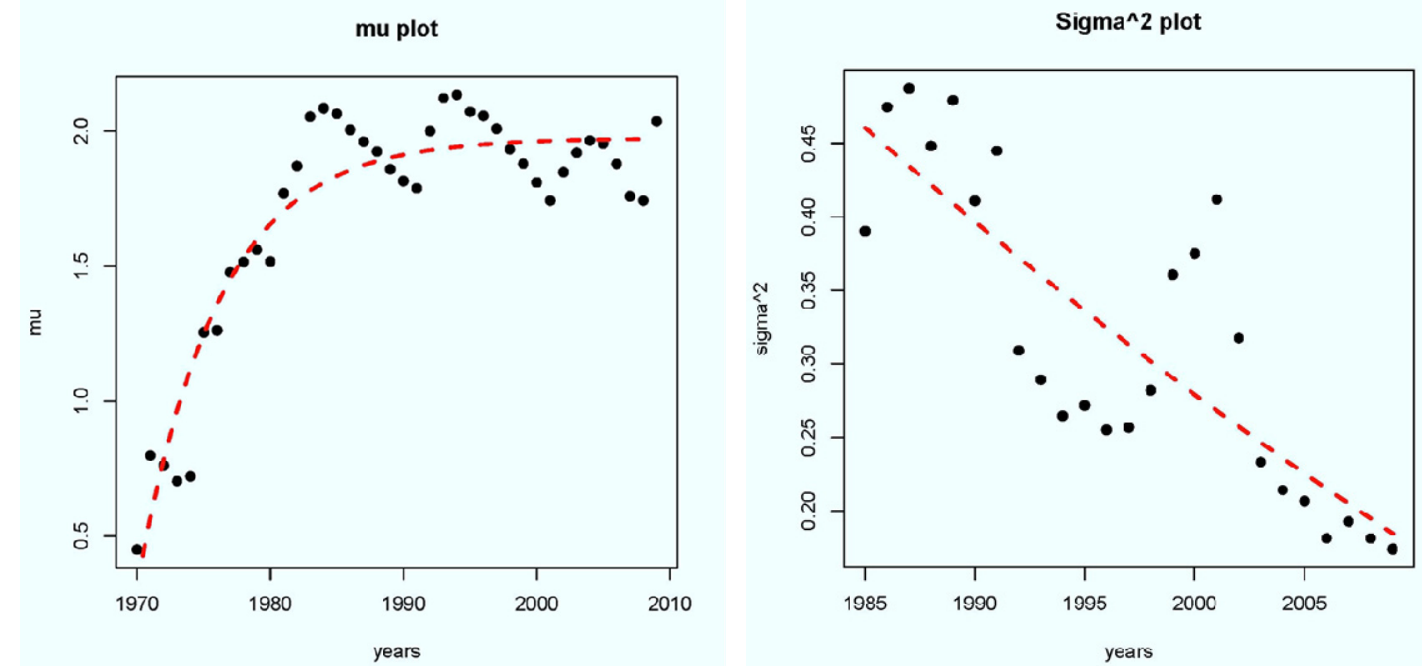

Figure 3b. OECD
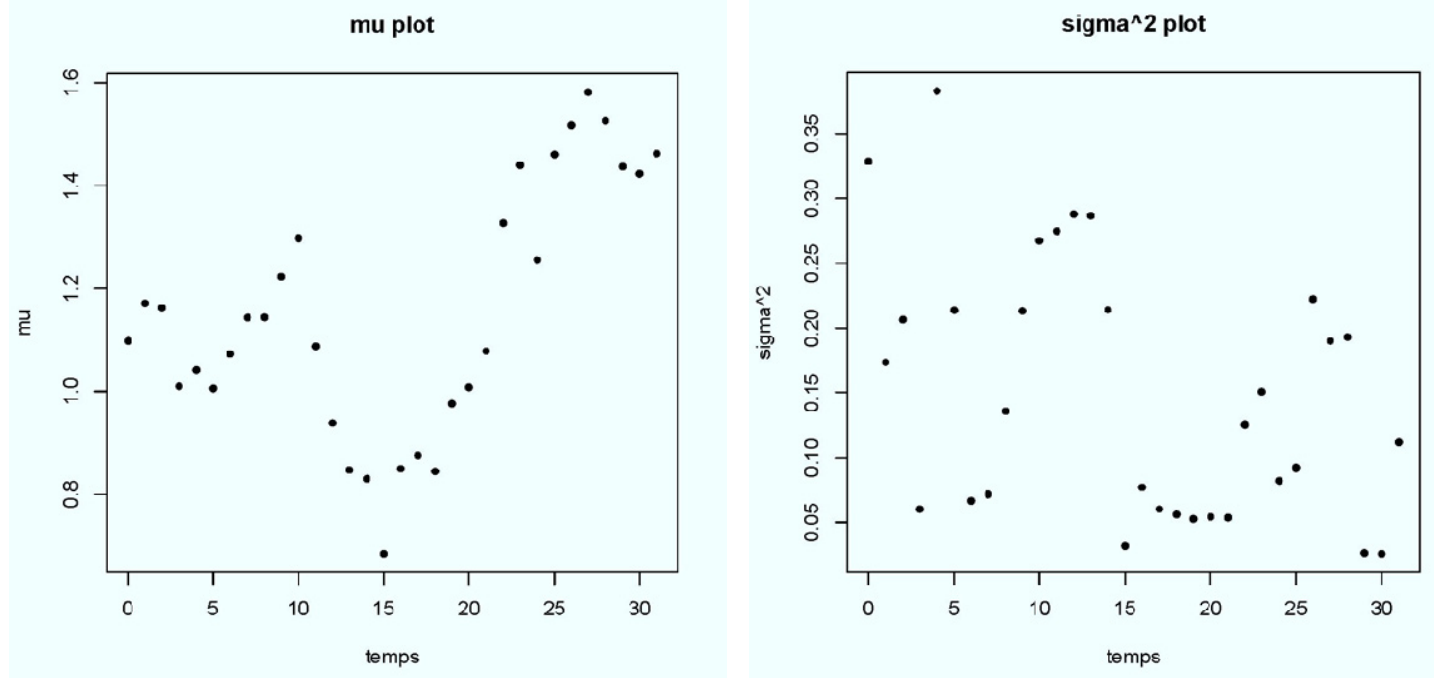

Figure 3c. Asia
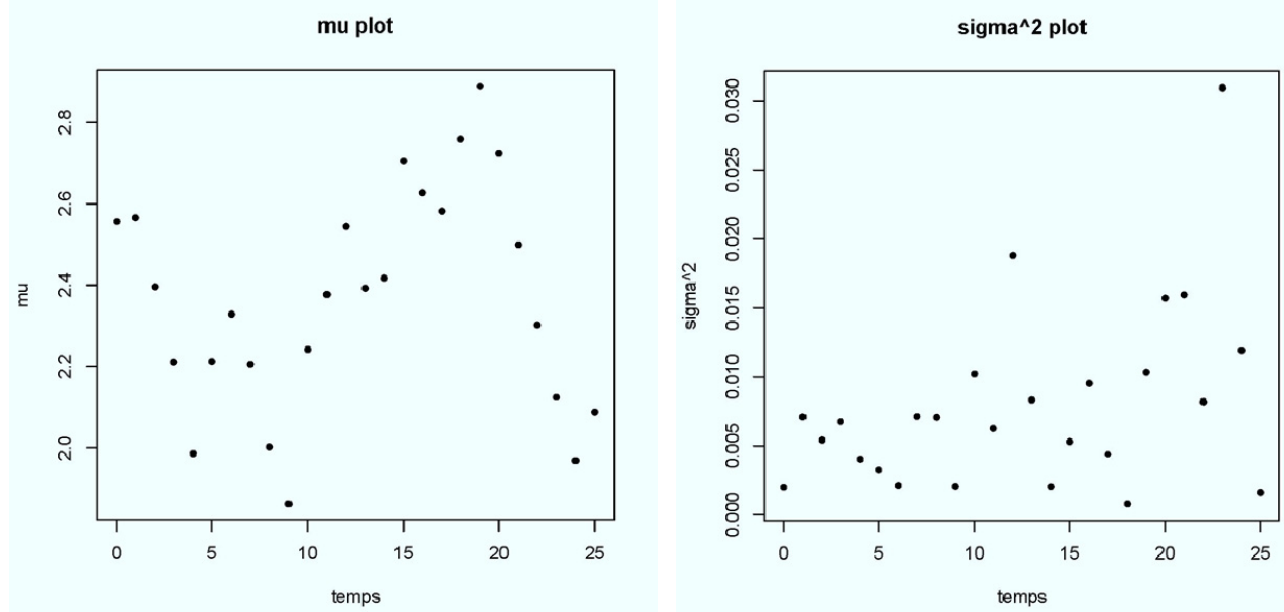

Figure 3d. South America 

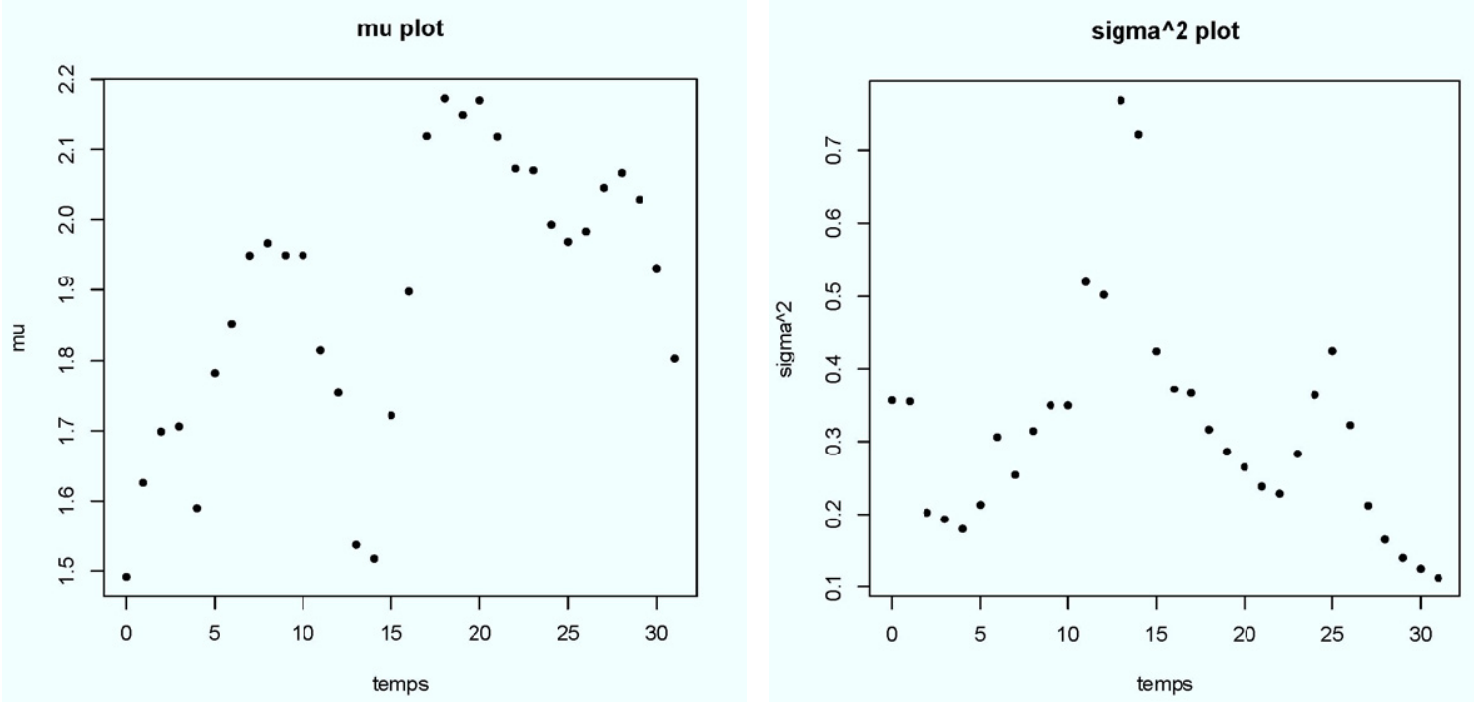

Figure 3e. OECD Europe

Figure 4 illustrates the evolution of the distribution of unemployment rates (log-normals) over time, superimposed on histograms which describe the time evolution of the distribution of the unemployment rates in the data (for selected years). The solid curves in these figures illustrate the distribution of the unemployment rates as predicted by the model, and the dotted curves illustrate the distribution of the unemployment rates in the data. The $\mathrm{x}$-axes on these figures denote rate of unemployment and the y-axes denote number of observations. The two panels represent the United States and OECD respectively.

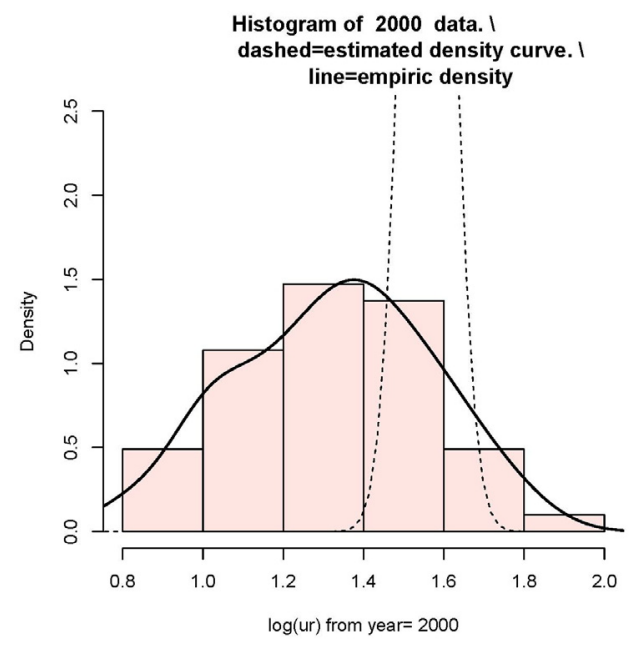



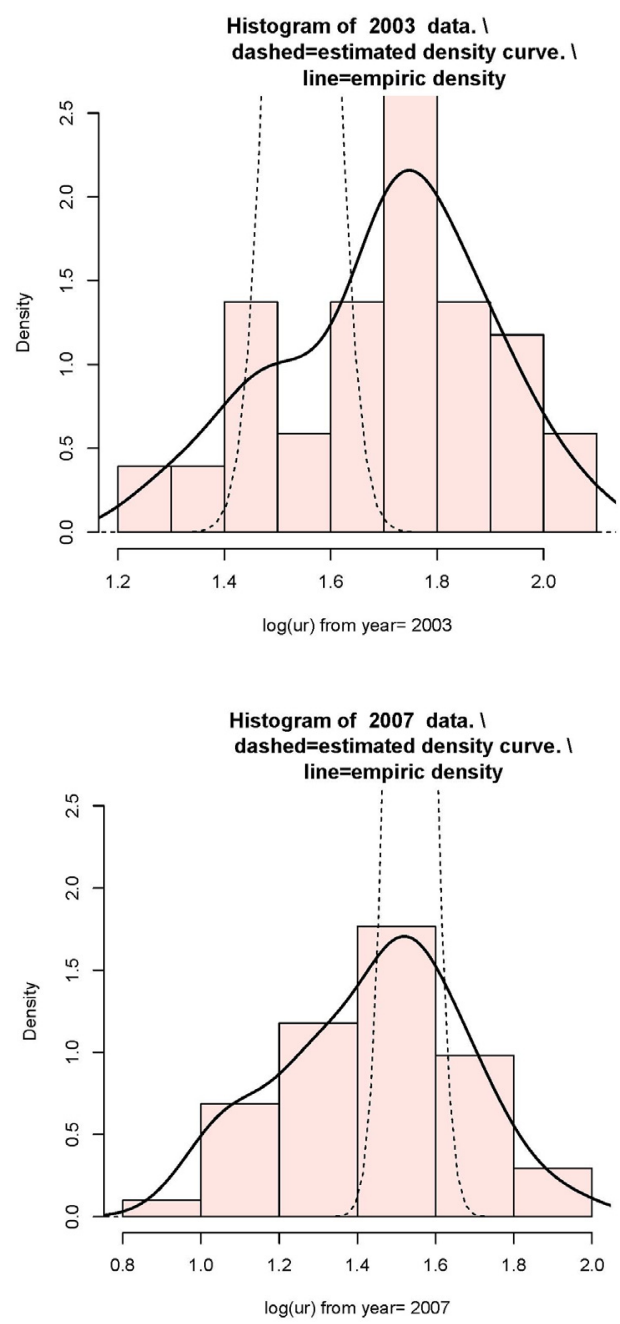

Figure 4a. United States

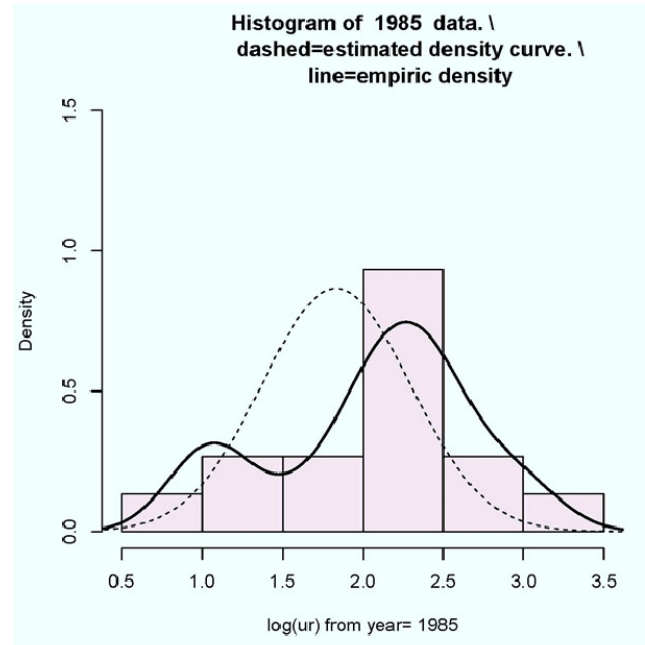



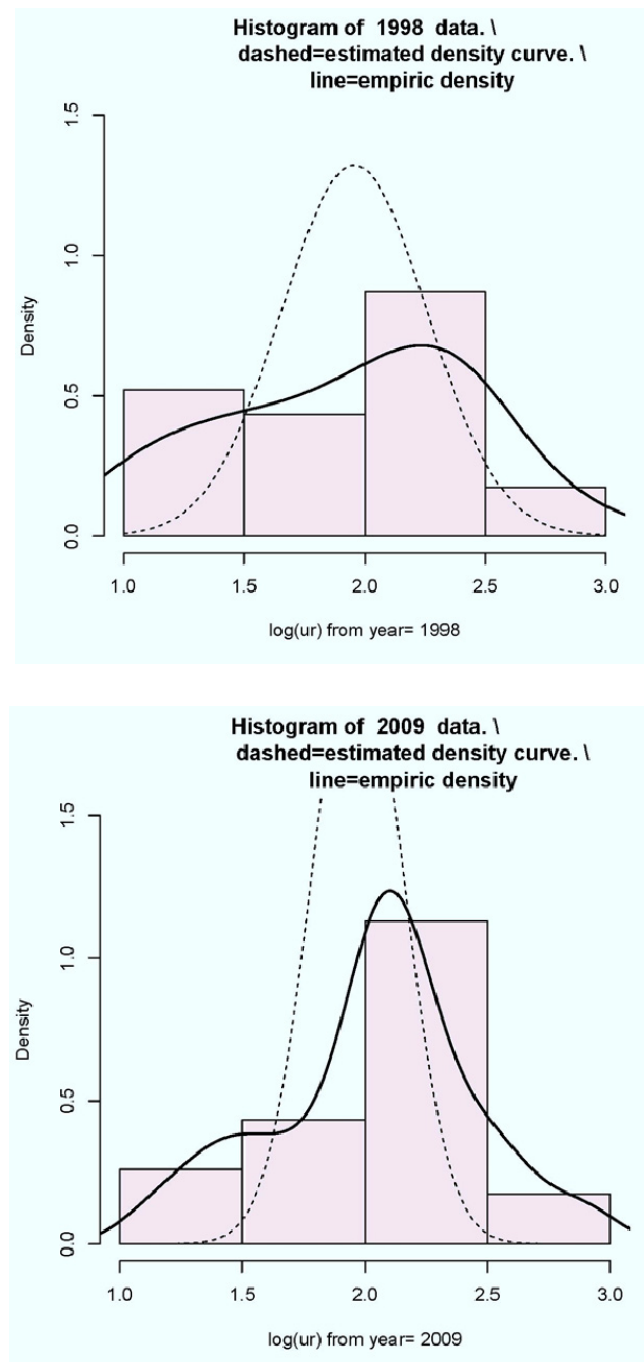

Figure 4b. OECD

Figure 4. Actual vs. Predicted Distributions for the United States and OECD respectively

Mark Hannay's assistance in the Estimation section of this paper is gratefully acknowledged.

\section{Concluding Remarks}

The present study provides a useful framework for thinking about macroeconomic policy questions, in particular with reference to the ability to explain changes in the inflation rate. When unemployment is below the natural rate, inflation can be expected to rise, and when it is above, inflation can be expected to fall. In general, a model that can successfully account for movements in unemployment will presumably be useful in analyzing how alternative policies would affect unemployment and what the welfare consequences of these policies would be. For example, the natural rate of unemployment is sometimes referred to as a proxy for broader macroeconomic equilibrium. A measure of the natural rate is therefore potentially useful for assessing the contribution of equilibrium fluctuations to overall macroeconomic volatility, the structural sources of equilibrium fluctuations, and the short run relationship between inflation and movements away from equilibrium (Stock and Watson (2002)).

By considerations of analytical tractability, the model developed in this paper constitutes a considerable simplification, for example with respect to homogeneity of parameters across countries. One may control for heterogeneity and introduce some determinant of the natural rate of unemployment and of the labor market dynamics. The present paper cites frictions in the labor market as a relevant determinant of the dynamics of unemployment when the stochastic equilibrium is reached. The first implication of such frictions may be to 
increase the natural rate of unemployment, and difference in frictions may generate difference in the natural rate of unemployment. The assumption that over time a set of countries share the same natural rate of unemployment, is more realistic across the states of the U.S., but also increasingly realistic in the European case moving forward. The dynamic process in the evolution of unemployment rates in Germany, France and Spain have been dramatically different over the last two decades. Once again, given the European integration efforts, the assumption that they would revert the same way and at the same pace becomes increasingly appropriate, were it not for the ongoing sovereign debt crisis which, at the time of writing, jeopardizes the whole European project. Finally, the assumption that the difference in unemployment volatility between these three countries is a matter of chance and due to different realizations of the shock process is also a strong assumption but becomes increasingly reasonable moving forward. The diffusion model developed in this paper is capable of extrapolation to a variety of realistic assumptions pertaining to the functional form of the parameters. These extensions would no doubt enrich the model and should prove insightful but only at the expense of considerable complexity. Given the importance of the natural rate of unemployment as a benchmark for gauging the state of the business cycle, appropriate techniques for its estimation are not without merit. The present paper illustrates that diffusion is a potential method to estimate the natural rate of unemployment and to monitor labor market dynamics.

\section{References}

Abraham, \& Lawrence. (1986). Cyclical Unemployment: Sectoral Shifts or Aggregate Disturbances. Journal of Political Economy, 94.

Alchian. (1950). Uncertainty, Evolution and Economic Theory. Journal of Political Economy, 58, 211-221.

Arrow. (1962). The Economic Implications of Learning-by-Doing, 29(3), 155-173.

Ball, \& Mankiw. (2002). The NAIRU in Theory and Practice. Journal of Economic Perspectives, 16(4).

Blanchard , \& Katz. (1992). The Evolution of Economic Regions. Brookings Papers on Economic Activity, no.1

Boianovsky, \& Presley. (2009). The Robertson Connection between the Natural Rates of Interest and Unemployment. Structural Change and Economic Dynamics, 20(2), 136-50.

Dickens. (2009). A New Method of Estimating Time Variation of the NAIRU.

Fair. (2000). Testing the NAIRU model for the United State. Review of Economics and Statistics, 82(1), 6471.

Feller. (1966). An Introduction to Probability and its Applications, New York, Wiley.

Forder. (2010). The Historical Place of the 'Friedman-Phelps' Expectations Critique. European Journal of the History of Economic Thought, 17(3), 493-511.

Gali. (2010). The Return of the Wage Phillips Curve'National Bureau of Economic Research. NBER Working Papers, 15758.

Gigerenzer, \& Selten. (2002). Bounded Rationality. Cambridge: MIT Press.

Gilks, Richardson, \& Spiegelhalter. (1996). Markov Chain Monte Carlo in Practice, London: Chapman and Hall.

Hashemi. (2000). An Evolutionary Model of the Size Distribution of Firms. Journal of Evolutionary Economics, $10(2), 2000,507-521$.

Hashemi. (2002). A Dynamic Model for the Cross-sectional Distribution of Unemployment Rates. Labour, 16(1), 89.

Kahneman. (2003). Maps of Bounded Rationality: Psychology for Behavioral Economics. The American Economic Review. 93(5), 1449-1475.

Karanassou, Sala, \& Snower. (2010). Philipps Curves and Unemployment Dynamics: A Critique and a Holistic Perspective. Journal of Economic Surveys, 24(1), 1-51. http://dx.doi.org/10.1111/j.1467-6419.2009.00598.x

King, \& Morley. (2007). In Search of the Natural Rate of Unemployment. Journal of Monetary Economics, 54, 550-564. http://dx.doi.org/10.1016/j.jmoneco.2005.11.002

Leon-Ledesma and McAdam (2004). Unemployment, hysterisis and transition. Scottish Journal of Political Economy, 51(3), 377-401. http://dx.doi.org/10.1111/j.0036-9292.2004.00311.x

Levine. (2009). Is Behavioral Economics Doomed' Max Weber Lectures? Cahuc and Zylberberg (2006): The Natural Survival of Work, MIT Press.

Nickell, Nunziata and Ochel (2005): 'Unemployment in the OECD since the 1960s. What do we know ? 
Economic Journal, 115, 1-27. http://dx.doi.org/10.1111/j.1468-0297.2004.00958.x

Nickell. (1997). Unemployment and labour market rigidities: Europe versus North America. Journal of Economic Perspectives, 11(3), 55-74.

Orphanides, \& Williams. (2010). Monetary policy mistakes and the evolution of inflation expectations' Federal Reserve Bank of San Francisco. Working Paper Series, 2010-12.

Petrongolo, \& Pissarides. (2008). The Ins and Outs of European Unemployment. American Economic Review, 98(2), 256-262. http://dx.doi.org/10.1257/aer.98.2.256

Phelps. (1994). Structural Slumps, Cambridge, MA: Harvard University Press.

Rogerson. (1997). Theory Ahead of Language in the Economics of Unemployment. Journal of Economic Perspectives, 11(1), 73-92.

Shimer, Robert. (2005). The Cyclical Behavior of Equilibrium Unemployment and Vacancies. American Economic Review, 95(1), 25-49. http://dx.doi.org/10.1257/0002828053828572

Simon. (1997). Models of Bounded Rationality, 3. MIT Press.

Simon. (1997). Models of bounded rationality: Empirically grounded economic reason. Cambridge, MA: The MIT Press.

Smith, \& Zoega (2009). Keynes, Investment, Unemployment and Expectations. International Review of Applied Economics, 23(4), 427-44.

Stock , \& Watson. (2002). Forecasting inflation. Journal of Monetary Economics, 44, 293-33.

Tanner. (1993). Tools for Statistical Inference. 2nd edition, New York: Springer-Verlag.

Yashiv, Eran. (2000). The Determinants of Equilibrium Unemployment. American Economic Review, 90(5), 1297-1322. http://dx.doi.org/10.1257/aer.90.5.1297 